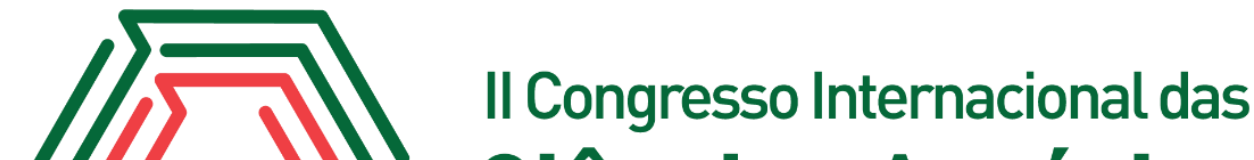 Ciências Agrárias COINTER - PDVAgro 2017
}

\section{EFEITO DO USO DE UMECTANTES NAS CARACTERÍSTICAS MICROBIOLÓGICAS DE QUALIDADE DA CARNE OVINA}

Apresentação: Pôster

Ana Paula Pinheiro de Assis ${ }^{1}$; Andreza Kelly Santos de Andrade ${ }^{2}$; Maria Carla da Silva Campêlo ${ }^{3}$; Lucas de Oliveira Soares Rebouças ${ }^{4}$; Patrícia de Oliveira Lima ${ }^{5}$

\section{Introdução}

A carne é o principal componente da dieta humana, sua importância se dá pelo grande aporte de nutrientes, especialmente proteínas, que são essenciais para o bom funcionamento do organismo. Segundo Mello (2014), a explosão demográfica, aliada aos efeitos da urbanização, a mudança dos hábitos alimentares e o aumento da renda nos países em desenvolvimento estão provocando uma elevação substancial no consumo de alimentos de origem animal.

A produção de carne ovina se insere nesse cenário como uma alternativa de grande potencial de crescimento. No entanto, não existem tradições ou hábitos que denotem o uso ou o consumo da carne na dieta da população (AZEVEDO \& ANTONIALLI, 2008). Tal afirmação é evidenciada quando se analisa os dados de consumo de per capita de carne no país apresentados por Alves et al. (2014): o consumo de carne ovina está em torno de 700 gramas, contra um consumo anual per capita de $39 \mathrm{~kg}$ de carne bovina, 44,5 kg carne de frango e $13 \mathrm{~kg}$ carne suína.

Dentre as muitas técnicas utilizadas pelas indústrias de produtos cárneos, a marinação de carnes se destaca. Tal técnica vem se desenvolvendo desde os anos 1980 em países desenvolvidos, e resulta em produtos bem-aceitos pelos consumidores, que reconhecem o incremento do sabor e a textura (DAGUER et al., 2010). O principio desta técnica é a aplicação de soluções e condimentos através de injeção, massagem ou imersão para conferir à carne melhorias nas suas características organolépticas e aumento no seu prazo de validade, no entanto, o impacto do uso de aditivos

\footnotetext{
${ }^{1}$ Pós-graduanda na Universidade Federal Rural do Semiárido, UFERSA, pinheiropaula87@hotmail.com

${ }^{2}$ Graduada em Zootecnia na Universidade Federal Rural do Semiárido, UFERSA, andrezak.andrade@gail.com

${ }^{3}$ Pós-graduanda na Universidade Federal Rural do Semiárido, UFERSA, carlacampelo2@hotmail.com

${ }^{4}$ Pós-graduando na Universidade Federal Rural do Semiárido, UFERSA; lucaslosr@gmail.com

${ }^{5}$ Docente na Universidade Federal Rural do Semiárido, UFERSA, pattlima@ufersa.edu.br
} 
sintéticos nessas soluções em diferentes tipos de produtos cárneos ainda demanda mais pesquisas (LEITE \& FIORELLI, 2013; DAGUER et al., 2010). De acordo com Gouveia (2006) os aditivos alimentares se tornaram virtualmente obrigatórios na alimentação moderna, sobretudo por sua capacidade de manter a qualidade e a validade dos alimentos comercializados.

\section{Fundamentação Teórica}

Segundo Garcia et al. (2012), técnicas como a marinação contribuem para melhorar a qualidade da carne. A técnica de marinação é uma prática antiga realizada com o auxílio de sais para diferenciar o sabor, melhorar a textura e aumentar a conservação de carnes. Segundo Tapasco, Restrepo e Suarez (2011), a marinação pode ser realizadas em qualquer tipo de carne, seja bovina, de frango, ovina, entre outras. Tradicionalmente são utilizadas três métodos para elaborar os produtos marinados: a imersão, a injeção e a massagem. Tal método tem gerado uma grande variedade de produtos, aumentando em proporção ao crescimento da demanda por produtos cárneos processados. Com isso, o impacto da utilização de soluções para incremento das características sensoriais da carne injetada/marinada tem demandado investigação científica relevante (GARCIA et al., 2012; DAGUER et al., 2010).

Os estudos sobre uso de diferentes concentrações destes aditivos na carne ovina marinada, seja isolado ou conjuntamente, ainda são escassos, fazendo-se necessárias pesquisas mais aprofundadas sobre os seus efeitos. Assim, objetivou-se com este trabalho avaliar o efeito do lactato de sódio, tripolifosfato de sódio e a da associação destes na qualidade da carne ovina.

\section{Metodologia}

A carne ovina utilizada foi oriunda de 24 animais sem padrão racial definido (SPRD) criados em sistema intensivo em propriedade particular no município de Governador Dix-Sept Rosado/RN. A idade média de abate dos animais foi de 6 meses e o abate dos mesmos foi conduzido no Abatedouro Frigorífico Industrial de Mossoró/RN (AFIM), seguindo protocolo padrão adotado pelo abatedouro. Após o abate, as carcaças foram armazenadas em câmara frigorifica, sob temperatura de 4 a $7^{\circ} \mathrm{C}$ durante o período de 24 horas, para que ocorresse o processo de transformação do músculo em carne. Em seguida, foram realizados os cortes e foi selecionado para a análise o músculo Longíssimos dorsi (contra-filé), que permaneceu sob refrigeração até o preparo das amostras em laboratório. 
Todo o preparo das amostras foi conduzido sob critérios de higiene e boas práticas de manipulação. A primeira etapa do preparo consistiu na separação da gordura e tecido conjuntivo da porção cárnea, que posteriormente foi subdividida em quatro lotes, sendo cada um submetido a um tratamento, onde três destes utilizaram da adição de lactato de sódio (LS) e tripolifosfato de sódio (TPF), além do controle. As amostras foram imersas por 15 minutos em soluções com as concentrações: F0: carne controle; F1: carne adicionada de 5\% de lactato de sódio; F2: carne adicionada de 5\% de tripolifosfato de sódio e F3: carne adicionada de 5\% de lactato de sódio + 2,5\% de tripolifosfato de sódio.

Todas as amostras foram armazenadas em temperatura de refrigeração, $4^{\circ} \mathrm{C} \pm 1^{\circ}$, e posteriormente submetidas a análises para verificação da qualidade microbiológica e físico-química da carne.

As análises microbiológicas foram realizadas no Laboratório de Inspeção de Produtos de Origem Animal (LIPOA) da Universidade Federal Rural do Semiárido (UFERSA). As amostras de carne ovina foram analisadas em triplicata e nos tempos de armazenamento: zero (dia zero), 3, 6, 9 e 12 dias sob temperatura de $4^{\circ} \mathrm{C} \pm 1^{\circ}$, sendo contabilizados os tempos subsequentes a partir do dia zero. Para as análises microbiológicas, foram pesadas, de maneira asséptica, $25 \mathrm{~g}$ de carne ovina e transferidas para sacos plásticos estéreis, onde foram acrescidos $225 \mathrm{~mL}$ de água peptonada tamponada estéril para posterior homogeneização em "Stomacher" durante 2 minutos, obtendo-se assim a diluição $10^{-1}$, a partir da qual foram obtidas as demais diluições decimais até $10^{-4}$. Após a diluição, as amostras foram submetidas às técnicas de contagem total de bactérias psicrotróficas e bactérias aeróbias mesófilas.

Para a análise estatística, os dados foram submetidos à análise de variância e teste de comparação de médias. Os efeitos dos diferentes tratamentos sobre cada variável foram comparados por meio do teste de Tukey, ao nível de 5\% de probabilidade, utilizando o SISVAR versão 5.6.

\section{Resultados e Discussões}

Os resultados da análise microbiológica estão apresentados na tabela 1.

Verificou-se que a utilização dos aditivos em carne ovina marinada mantida sob refrigeração não foi suficiente para retardar a proliferação de microrganismos mesófilos. As amostras de carne 
ovina estavam fora do limite aceitável para produtos cárneos, estabelecido pela legislação brasileira através da resolução $\operatorname{RDC}^{\circ} 12$ de 02 de janeiro de 2001 (BRASIL, 2001).

Tabela 1. Contagem de microrganismos mesófilos e psicrotróficos aeróbios durante armazenamento refrigerado em carne ovina marinada. Fonte: Própria

\begin{tabular}{|c|c|c|c|c|c|c|}
\hline \multirow{2}{*}{$\begin{array}{c}\text { Dias de } \\
\text { armazenamento }\end{array}$} & \multirow{2}{*}{ Análises } & \multicolumn{4}{|c|}{ TRATAMENTOS } & \multirow{2}{*}{$\mathrm{CV}(\%)$} \\
\hline & & CONTROLE & $\mathrm{LS}$ & TPF & LSTPF & \\
\hline 0 & Mesófilos & $6,4 \mathrm{Ab}$ & $6,4 \mathrm{Ab}$ & $6,4 \mathrm{Ab}$ & $6,4 \mathrm{Ab}$ & \multirow{2}{*}{0} \\
\hline 3 & $\left(\log _{10} \mathrm{UFC} / \mathrm{g}\right)$ & 7,4 Aa & $7,4 \mathrm{Aa}$ & 7,4 Aa & 7,4 Aa & \\
\hline 0 & Psicotróficos & $6,40 \mathrm{Ab}$ & $5,80 \mathrm{BCb}$ & $5,70 \mathrm{Cb}$ & $5,90 \mathrm{Bb}$ & \multirow{2}{*}{0,75} \\
\hline 3 & $\left(\log _{10} \mathrm{UFC} / \mathrm{g}\right)$ & 7,4 Aa & 7,4 Aa & 7,4 Aa & 7,4 Aa & \\
\hline
\end{tabular}

Com relação aos microrganismos psicotróficos, pode-se observar que houve um efeito inicial (dia 0) de diminuição da carga microbiana, provavelmente relacionado à variação imediata de $\mathrm{pH}$ provocada pelos aditivos, mas tal efeito não inibiu a proliferação microbiana ao longo do período analisado. A carne e seus produtos derivados apresentam-se como substratos excelentes para o desenvolvimento microbiano, fato relacionado com sua rica composição químico e com seus caracteres físico-químicos. Os microrganismos podem agir neste substrato, como agentes causadores de deterioração, diminuindo o valor nutritivo e/ou como potenciais vetores de processos patológicos (SILVA et al., 2004).

\section{Conclusões}

Nesse estudo os aditivos isolados ou sua combinação não tiveram efeito antimicrobiano previsto, possivelmente devido à contaminação prévia das amostras.

\section{Referências}

ALVES, Luís Gustavo Castro et al. Produção de carne ovina com foco no consumidor. Enciclopédia Biosfera, Goiânia, v. 10, n. 18, p.2399-2014, jul. 2014. Disponível em: <http://www.conhecer.org.br/enciclop/2014a/AGRARIAS/producao de carne.pdf>. Acesso em: 10 Setem. 2017. 
AZEVEDO, Filipe Manuel Ventura Magalhães da Cruz; ANTONIALL, Marcelo. Produção e comercialização de carne de ovinos na região metropolitana de Belo Horizonte-MG. 2008. Disponível em: <http://www.sober.org.br/palestra/9/198.pdf>. Acesso em: 30 Setem. 2017.

BRASIL. Leis, decretos, etc. Resolução RDC n.12, 02 de janeiro de 2001 da Agência Nacional de Vigilância Sanitária. Aprova o Regulamento Técnico sobre Padrões Microbiológicos para Alimentos. Diário Oficial, Brasília, 10 jan. 2001, Seção 1, p.45-47.

DAGUER, Heitor et al. Controle da utilização de ingredientes não cárneos para injeção e marinação de carnes. Ciência Rural, [s.1.], v. 40, n. 9, p.2037-2046, set. 2010. Fap UNIFESP (SciELO). http://dx.doi.org/10.1590/s0103-84782010005000138.

GARCIA, Rodrigo Garófallo et al. Qualidade de filés de peito de frango de corte marinados e maturados. Revista Agrarian, Dourados, v. 5, n. 16, p.166-173, maio 2012.

GOUVEIA, Flávia. Indústria de alimentos: no caminho da inovação e de novos produtos. Inovação UNIEMP, Campinas, v. 2, n. 5, dic. 2006 .

HONORATO, Thatyan Campos et al. Aditivos alimentares: aplicações e toxicologia. Revista Verde de Agroecologia e Desenvolvimento Sustentável, Mossoró, v. 8, n. 5, p.1-11, dez. 2013.

LEITE, Cláudio Eduardo Cartabiano; FIORELLI, Rogério Balotin. DESENVOLVIMENTO DE UM MARINADO A BASE DE CARNE DE POEDEIRAS DE DESCARTE. 2013. 54 f. TCC (Graduação) - Curso de Tecnologia de Alimentos, Universidade Tecnológica Federal do Paraná, Francisco Beltrão, 2013.

MELLO, Jéssica Mello de. O bem-estar no manejo pré-abate de frangos e sua relação com a qualidade da carne. 2014. 58 f. TCC (Graduação) - Curso de Medicina Veterinária, Universidade Federal do Rio Grande do Sul, Porto Alegre, 2014.

SILVA, N. V. da et al. Características de carcaça e carne ovina: uma abordagem das variáveis metodológicas e fatores de influência. Acta Veterinária Brasilica, Mossoró, v. 2, n. 4, p.103-110, jan. 2008.

SILVA, C. A.; SOUSA, E. L.; SOUSA, C. P. Estudo da qualidade sanitária da carne moída comercializada na cidade de João Pessoa, PB. Revista Higiene Alimentar. 18(121):90-94, jun. 2004.

TAPASCO Z, YOMAIRA; RESTREPO M, DIEGO ALONSO; SUAREZ M, HÉCTOR. Efecto Reológico De Hidrocoloides Sobre La Salmuera De Marinado De Carne Bovina. Rev.Bio.Agro, Popayán, v. 9, n. 2, p. 23-31, Dec. 2011. 